\title{
High prevalence of HPV infection in the remote villages of French Guiana: an epidemiological study
}

\author{
A. ADENIS ${ }^{1}$, V. DUFIT ${ }^{1}$, M. DOUINE ${ }^{1}$, F. CORLIN ${ }^{1}$, G. AYHAN ${ }^{1}$, \\ F. NAJIOULLAH ${ }^{2}$, V. MOLINIE ${ }^{3}$, P. BROUSSE ${ }^{4}$, G. CARLES ${ }^{5}$, V. LACOSTE ${ }^{6}$, \\ R. CESAIRE ${ }^{2}$ AND M. NACHER ${ }^{1,7}$ * \\ ${ }^{1}$ Centre d'Investigation Clinique Antilles-Guyane, CIC INSERM 1424, Centre hospitalier de Cayenne, Cayenne, \\ French Guiana \\ ${ }^{2}$ Laboratoire de Virologie, CHU de la Martinique, Fort de France, Martinique \\ ${ }^{3}$ Laboratoire d'anatomopathologie, CHU de la Martinique, Fort de France, Martinique \\ ${ }^{4}$ Département des Centres délocalisés de prévention et de soins, Centre Hospitalier de Cayenne, Cayenne, French \\ Guiana \\ ${ }^{5}$ Service de Gynecologie Obstétrique, Centre Hospitalier de l'Ouest Guyanais, Saint Laurent du Maroni, French \\ Guiana \\ ${ }^{6}$ Laboratoire des Interactions Virus-Hôtes, Institut Pasteur de la Guyane, Cayenne, French Guiana \\ ${ }^{7}$ EA 3593, Ecosystèmes Amazoniens et Pathologie Tropicale, Université de Guyane, Cayenne, French Guiana
}

Received 4 July 2016; Final revision 21 October 2016; Accepted 14 December 2016;

first published online 16 January 2017

\section{SUMMARY}

Cervical cancer is the second most frequent cancer in women in French Guiana. Studies have shown that populations living in the remote areas of the interior have early sexual debut and that multiple sexual partnerships are common. The objective of the present study was thus to determine the prevalence of human papillomavirus (HPV) infection in these areas. A study was conducted in women aged 20-65 years with previous sexual activity. Women were included on a voluntary basis after using local media and leaders to inform them of the visit of the team. HPV infection was defined by the detection of HPV DNA using the Greiner Bio-One kit. In addition to HPV testing cytology was performed. The overall age-standardized prevalence rate was $35 \%$. There was a $U$-shaped evolution of HPV prevalence by age with women aged $>50$ years at highest risk for HPV, followed by the 20-29 years group. Twenty-seven percent of women with a positive HPV test had normal cytology. Given the high incidence of cervical cancer in French Guiana and the high prevalence of HPV infections the present results re-emphasize the need for screening for cervical cancer in these remote areas. Vaccination against HPV, preferably with a nonavalent vaccine, also seems an important prevention measure. However, in this region where a large portion of the population has no health insurance, this still represents a challenge.

Key words: Epidemiology, French Guiana, HPV, prevalence.

\section{INTRODUCTION}

Cervical cancer is a global public health problem caused by persistent human papillomavirus (HPV) infection

\footnotetext{
* Author for correspondence: Professor M. Nacher, CIC INSERM 1424, Centre Hospitalier de Cayenne, rue des Flamboyants, 97300, Cayenne, French Guiana. (Email: mathieu.nacher66@gmail.com)
}

leading to malignancy [1]. For women, it ranks second in terms of cancer incidence and mortality worldwide, and it ranks first in several developing countries. The global burden estimates suggest that annual incidence is 510000 and mortality is 288000 each year worldwide.

In France, cervical cancer is ranked number 8 in terms of cancer incidence [2]. In the French overseas 
territories in the Americas the incidence rates are situated between what is observed in mainland France and the Caribbean [3], one of the most affected regions worldwide [4]. In French Guiana, cervical cancer is the second most frequent cancer in females [5], still causing significant mortality [6]. In 2002-2005, the standardized incidence of cervical cancer was 30.3/100 000 women, which was close to that of neighbouring Brazil [7]. French Guiana is a sparsely populated region covered by primary forest, with populations living in remote parts of the territory only accessible by boat. Despite a network of health centres connected to the main hospital, there are some difficulties in accessing care. It was recently shown that despite the absence of a significant difference in incidence between rural areas and urban areas, there were some differences in the diagnostic delays with $77 \%$ of the women from the rural areas with lesions metastasizing beyond the cervix vs. 44\% for women living in urban areas [5]. Health professionals concur that given the early start of sex life in populations living in these remote parts [8], the risk of cervical lesions due to HPV should be high. In these remote areas, sexual transmission has also driven the HIV epidemic, which has soared from zero to over $1 \%$ within a decade [9]. Given that HPV16-18 are involved in 73\% of cervical cancers in Europe, vaccination against these genotypes is now recommended in France. However, little is known about the epidemiology of HPV in French Guiana, a French territory with very different populations and a very different pathogen environment from that of mainland France. The relative isolation of Amerindian and Maroon populations may thus lead to singular epidemiological features. The objective of the present study was thus to describe the prevalence of HPV infections in general, the prevalence of the different genotypes and of cytological anomalies in women aged 20-65 years living in the remote areas of French Guiana.

\section{METHODS}

\section{Study population}

The source population was women living in the remote villages on the Maroni and Oyapock rivers. The target population was women aged 20-65 years having previously had sexual activity. Enrolment in the study took place between December 2012 and September 2014.

Inclusion criteria. All women from the target population.
Exclusion criteria. Women with a history of hysterectomy, pregnant women ( $>3$ months pregnant).

Data collection. At the time of enrolment a short questionnaire was completed to collect socioeconomic and demographic data, gynecological and obstetrical history.

\section{Study conduct}

Before starting enrolment, communication missions were undertaken in all villages in order to sensitize the local populations on this public health problem. Traditional authorities and health centre workers were also informed. Local radio messages informed the population of the dates of the study team's presence in the village. Women wishing to be screened came to the health centre where the project was explained to them. When individuals agreed to participate in the study, a questionnaire was completed and samples were taken and kept in a cooler until the end of the mission. The samples were then sent to the Virology laboratory of Fort de France Hospital, Martinique, where extraction and genotyping were performed using an automated method in order to reduce the risk of error and contamination. DNA extraction was performed using a minimum of $2 \mathrm{ml}$ of the sample in liquid phase.

HPV infection was defined by the detection of HPV DNA using the Greiner Bio-One kit. This kit allows the identification of potentially oncogenic HPV genotypes: $16,18,31,33,35,39,45,51,52,53,56,58,59$, $66,68,70,73,82$ and of low-risk HPV genotypes: 6 , $11,40,42,43,44,55$. This kit allowed the identification of multiple infections. Cytological anomalies were described using the 2001 Bethesda classification.

All results were sent to attending physicians for medical care. When HPV was positive and cytology was negative, a gynaecological follow-up was recommended 1 year later with a cervical smear and an HPV test to verify if HPV positivity had disappeared or if cytological lesions were present. If both HPV and cytology were positive, colposcopy was proposed.

\section{Ethical and regulatory aspects}

Although it has been shown that HPV tests are superior to cytology for the detection of cervical cancer, in France the HPV test is only reimbursed when the patient has a cytological examination revealing 
Table 1. Proportion of human papillomavirus (HPV)-positive women stratified by different demographic and life-history covariates

\begin{tabular}{|c|c|c|c|c|c|}
\hline & \multirow[b]{2}{*}{$N$} & \multirow[b]{2}{*}{ Overall $(\%)$} & \multicolumn{3}{|c|}{ Proportion of women positive for HPV } \\
\hline & & & Any HPV (\%) & High risk $(\%)$ & Low risk $(\%)$ \\
\hline Total & 643 & $100 \cdot 0$ & $33 \cdot 3$ & $27 \cdot 8$ & $9 \cdot 2$ \\
\hline \multicolumn{6}{|l|}{ Age (years) } \\
\hline $20-29$ & 181 & $28 \cdot 1$ & $37 \cdot 0$ & $32 \cdot 6$ & $7 \cdot 2$ \\
\hline $30-39$ & 231 & $35 \cdot 9$ & $32 \cdot 0$ & $25 \cdot 1$ & $10 \cdot 4$ \\
\hline $40-49$ & 140 & $21 \cdot 8$ & $23 \cdot 6$ & $19 \cdot 3$ & $6 \cdot 4$ \\
\hline $50-64$ & 91 & $14 \cdot 2$ & $44 \cdot 0$ & $38 \cdot 5$ & $14 \cdot 3$ \\
\hline \multicolumn{6}{|l|}{ Education } \\
\hline Never & 209 & $32 \cdot 5$ & $35 \cdot 9$ & $30 \cdot 1$ & $11 \cdot 0$ \\
\hline Low & 212 & $33 \cdot 0$ & $34 \cdot 9$ & $29 \cdot 2$ & $9 \cdot 0$ \\
\hline Intermediate and high & 219 & $34 \cdot 1$ & $28 \cdot 3$ & $23 \cdot 7$ & $7 \cdot 3$ \\
\hline Missing & 3 & $0 \cdot 5$ & $100 \cdot 0$ & $66 \cdot 7$ & $33 \cdot 3$ \\
\hline \multicolumn{6}{|l|}{ Native language } \\
\hline Maroon languages & 266 & $41 \cdot 4$ & $36 \cdot 1$ & $30 \cdot 1$ & $10 \cdot 5$ \\
\hline Amerindian languages & 212 & $33 \cdot 0$ & $34 \cdot 0$ & $28 \cdot 8$ & $9 \cdot 0$ \\
\hline Portuguese & 114 & $17 \cdot 7$ & $26 \cdot 3$ & $22 \cdot 8$ & $5 \cdot 3$ \\
\hline Others & 51 & $7 \cdot 9$ & $31 \cdot 4$ & $23 \cdot 5$ & $11 \cdot 8$ \\
\hline \multicolumn{6}{|c|}{ Age at first sexual intercourse } \\
\hline$<15$ years & 120 & $18 \cdot 7$ & $30 \cdot 0$ & $25 \cdot 8$ & $5 \cdot 0$ \\
\hline $15-17$ years & 237 & $36 \cdot 9$ & $32 \cdot 9$ & $28 \cdot 3$ & $8 \cdot 9$ \\
\hline$\geqslant 18$ years & 86 & $13 \cdot 4$ & $32 \cdot 6$ & $26 \cdot 7$ & $12 \cdot 8$ \\
\hline Missing & 200 & $31 \cdot 1$ & $36 \cdot 0$ & $29 \cdot 0$ & $10 \cdot 5$ \\
\hline \multicolumn{6}{|c|}{ No. of sexual partners in past year } \\
\hline 0 & 46 & $7 \cdot 2$ & $41 \cdot 3$ & $37 \cdot 0$ & $15 \cdot 2$ \\
\hline 1 & 387 & $60 \cdot 2$ & $33 \cdot 1$ & $27 \cdot 9$ & $8 \cdot 3$ \\
\hline$\geqslant 2$ & 72 & $11 \cdot 2$ & $30 \cdot 6$ & $26 \cdot 4$ & $8 \cdot 3$ \\
\hline Missing & 138 & $21 \cdot 5$ & $32 \cdot 6$ & $25 \cdot 4$ & $10 \cdot 1$ \\
\hline \multicolumn{6}{|l|}{ Parity } \\
\hline $0-1$ & 104 & $16 \cdot 2$ & $34 \cdot 6$ & $32 \cdot 7$ & $7 \cdot 7$ \\
\hline $2-3$ & 196 & $30 \cdot 5$ & $29 \cdot 6$ & $24 \cdot 0$ & $8 \cdot 2$ \\
\hline $4-5$ & 154 & $24 \cdot 0$ & $33 \cdot 1$ & $27 \cdot 9$ & $7 \cdot 1$ \\
\hline$>5$ & 189 & $29 \cdot 4$ & $36 \cdot 5$ & $29 \cdot 1$ & $12 \cdot 7$ \\
\hline \multicolumn{6}{|l|}{ Contraceptives } \\
\hline Never & 424 & $65 \cdot 9$ & $31 \cdot 8$ & $27 \cdot 6$ & $9 \cdot 0$ \\
\hline Oral & 104 & $16 \cdot 2$ & $37 \cdot 5$ & $29 \cdot 8$ & $9 \cdot 6$ \\
\hline Other & 115 & $17 \cdot 9$ & $34 \cdot 8$ & $27 \cdot 0$ & $9 \cdot 6$ \\
\hline \multicolumn{6}{|l|}{ Smoking } \\
\hline Yes & 33 & $5 \cdot 1$ & $30 \cdot 3$ & $18 \cdot 2$ & $12 \cdot 1$ \\
\hline No & 610 & $94 \cdot 9$ & $33 \cdot 4$ & $28 \cdot 4$ & $9 \cdot 0$ \\
\hline
\end{tabular}

atypical cells of undetermined significance (ASCUS). Here, all patients received the HPV test and cytology free of charge. All participants supplied written informed consent. Regulatory and ethical approvals were given by the Comité d'Evaluation Ethique de l'Inserm (CEEI), approval no. 12-064; the Comité Consultatif sur le Traitement de l'Information en matière de Recherche dans le domaine de la Santé (CCTIRS), no. 12.310; the Commission Nationale de l'Informatique et des Libertés (CNIL), no. 912 459; and the Comité de Recherche Clinique (CoRC)
Pasteur Institute, no. 2012-15. The study was funded by the European Regional Development Fund (FEDER presage no. 30814).

\section{Data analysis}

Prevalence was obtained by dividing the number of women infected by at least one HPV genotype (high grade or low grade) by the total number of women included. For specific genotypes, prevalence was 


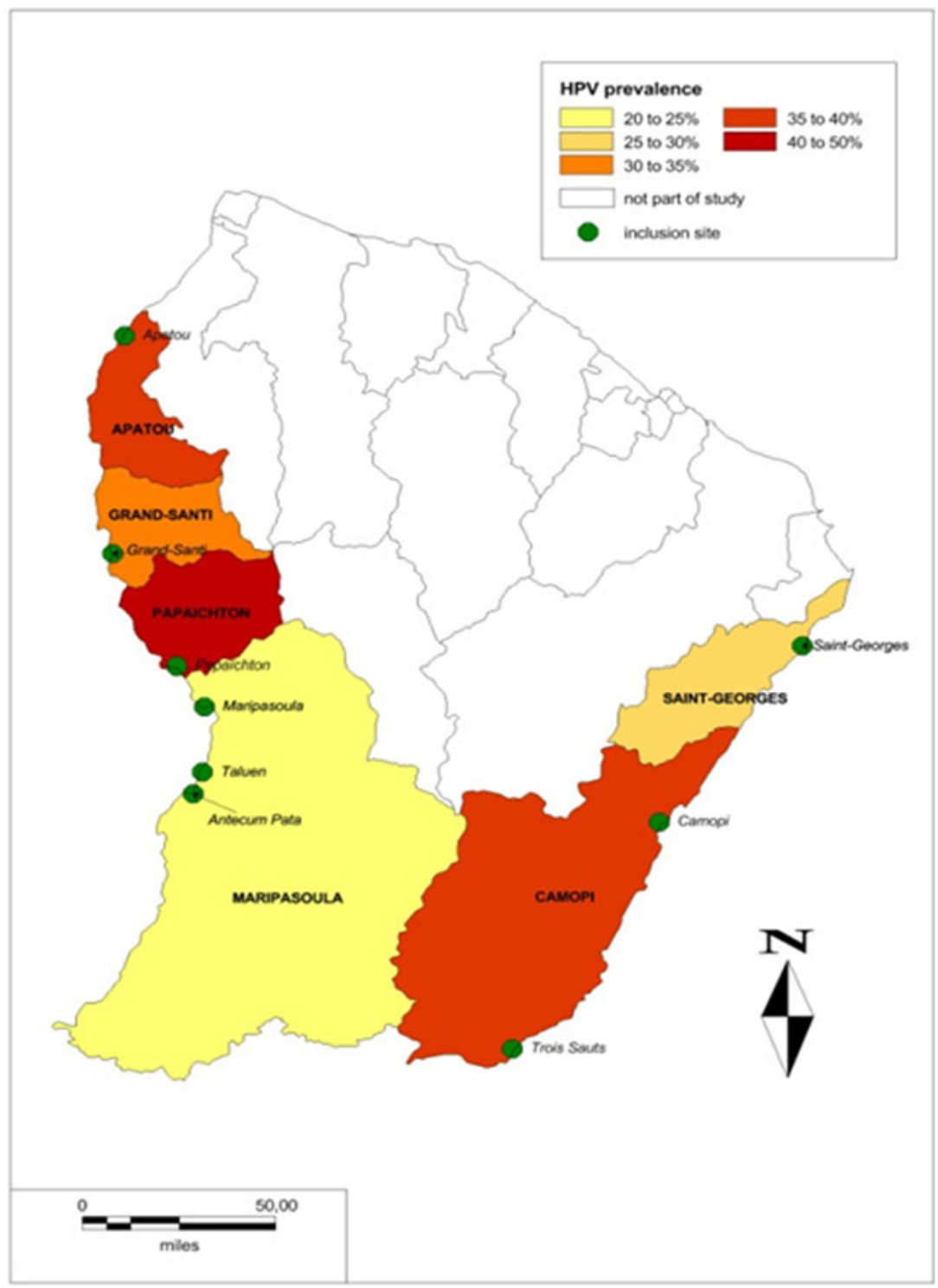

Fig. 1. The geographical differences in human papillomavirus (HPV) prevalence.

obtained by dividing the number of women infected by that specific genotype by the total number of women included in the study. Prevalence of cytological anomalies was obtained by dividing the number of women with at least one cytological anomaly by the total number of women with an interpretable cytological examination.

The standardized HPV prevalence rate used the direct standardization method with the world population as a reference.

Unconditional multiple logistic regression was used to predict the variables associated with having a positive HPV test. Different age group-specific models were performed. Categorical variables were transformed into indicator variables. The data were analysed using
Stata v. 13 (StataCorp., USA). Mapping was performed using Mapinfo v. 12.0 (USA).

\section{RESULTS}

Overall, the population of women living in the remote villages was estimated at 5712 on the Maroni river and 1209 on the Oyapock river. A total of 643 women (406 on the Maroni river, 237 on the Oyapock river) were included and 51 were excluded due to exclusion criteria. On the Maroni river 117 were included in Apatou, 69 in Grand Santi, 86 in Papaïchton, 65 in Maripasoula, 32 in Taluen, and 37 in Antecume Pata. On the Oyapock river 98 were included in 
Table 2. Distribution of human papillomavirus (HPV) genotypes by age

\begin{tabular}{|c|c|c|c|c|c|}
\hline & $\begin{array}{l}\text { Age }<30 \text { years } \\
(N=181) \\
n\end{array}$ & $\begin{array}{l}\text { Age } 30-39 \text { years } \\
(N=231) \\
n\end{array}$ & $\begin{array}{l}\text { Age } \geqslant 40 \text { years } \\
(N=231) \\
n\end{array}$ & $\begin{array}{l}\text { All ages } \\
(N=643) \\
n\end{array}$ & Prevalence $(\%)$ \\
\hline \multicolumn{6}{|c|}{ HPV high-risk type } \\
\hline 52 & 10 & 8 & 11 & 29 & $4 \cdot 51$ \\
\hline 16 & 8 & 8 & 5 & 21 & $3 \cdot 27$ \\
\hline 68 & 6 & 4 & 11 & 21 & $3 \cdot 27$ \\
\hline 31 & 8 & 6 & 5 & 19 & $2 \cdot 95$ \\
\hline 53 & 6 & 5 & 8 & 19 & $2 \cdot 95$ \\
\hline 58 & 7 & 6 & 4 & 17 & $2 \cdot 64$ \\
\hline 18 & 3 & 6 & 6 & 15 & $2 \cdot 33$ \\
\hline 56 & 8 & 3 & 4 & 15 & $2 \cdot 33$ \\
\hline 51 & 3 & 6 & 3 & 12 & $1 \cdot 87$ \\
\hline 39 & 4 & 2 & 4 & 10 & $1 \cdot 56$ \\
\hline 70 & 1 & 4 & 5 & 10 & $1 \cdot 56$ \\
\hline 45 & 1 & 6 & 2 & 9 & $1 \cdot 40$ \\
\hline 66 & 4 & 4 & 1 & 9 & $1 \cdot 40$ \\
\hline 35 & 2 & 2 & 3 & 7 & 1.09 \\
\hline 73 & 2 & 1 & 2 & 5 & 0.78 \\
\hline 33 & 0 & 2 & 1 & 3 & 0.47 \\
\hline 59 & 2 & 0 & 1 & 3 & 0.47 \\
\hline 82 & 2 & 1 & 0 & 3 & $0 \cdot 47$ \\
\hline \multicolumn{6}{|c|}{ HPV low-risk type } \\
\hline $44 / 55$ & 5 & 12 & 14 & 31 & $4 \cdot 82$ \\
\hline 42 & 4 & 6 & 4 & 14 & $2 \cdot 18$ \\
\hline 6 & 3 & 4 & 0 & 7 & 1.09 \\
\hline 40 & 1 & 2 & 3 & 6 & 0.93 \\
\hline 43 & 0 & 0 & 2 & 2 & 0.31 \\
\hline 11 & 0 & 0 & 1 & 1 & $0 \cdot 16$ \\
\hline
\end{tabular}

Saint Georges, 60 in Camopi, and 79 in Trois Sauts. The ratio between the number of women included in each village and the estimated target population number in each village ranged between a minimum of $6 \%$ in Grand Santi to $41 \cdot 7 \%$ in Camopi. Overall, $9 \cdot 3 \%$ of women from the target population entered the study. Overall, sexual relations started at a young age with $27 \%$ of the surveyed women had their first sexual relations before age 15 , and $50 \%$ before age 16 .

Table 1 shows very high HPV prevalence notably for high-risk viruses. The overall age-standardized prevalence rate was $35 \%$. There was a $U$-shaped evolution of overall HPV prevalence by age and high-risk HPV prevalence by age, with women aged $>50$ years at highest risk for HPV, followed by those aged 20-29 years. Maroon language was associated with a greater HPV prevalence whereas Portuguese language was associated with a lower prevalence. Other risk factors such as number of sex partners, parity, age at first sex, education, contraception, or smoking were not significantly linked to differences in HPV prevalence. None of the women had declared receiving the HPV vaccine.
Figure 1 shows the geographical differences in HPV prevalence with the lower part of the Maroni river having the highest prevalence. Table 2 shows that HPV52 was the most frequent high-risk virus. HPV16 was the second most frequent genotype in women aged $<40$ years, although it appeared less frequent in women aged $>40$ years. Overall, the prevalence of HPV16 or 18 exceeded $5 \%$ of tested women.

Overall, 139 women had single HPV infections, 53 had double infections, and 22 had $\geqslant 3$ different HPV genotypes.

A very large proportion $(N=147,27 \cdot 2 \%)$ of women with normal cytology had a positive HPV test.

Tables 3 and 4 show multiple regression models predicting HPV positivity for different covariates. Few variables predicted HPV positivity. In the global models women aged 20-29 years and women aged 50-64 years were at higher risk of having a positive HPV test, and of having a high-risk genotype than other age groups, as shown in Figure 1. Table 4 shows that education was independently associated with HPV positivity in women aged 20-29 years but 
Table 3. Multivariate logistic regression models predicting human papillomavirus (HPV) prevalence

\begin{tabular}{|c|c|c|c|c|c|c|}
\hline & \multicolumn{2}{|c|}{$\begin{array}{l}\text { Positive for HPV } \\
\text { detection }\end{array}$} & \multicolumn{2}{|c|}{$\begin{array}{l}\text { Positive for HPV } \\
\text { high-risk type }\end{array}$} & \multicolumn{2}{|c|}{$\begin{array}{l}\text { Positive for HPV low-risk } \\
\text { type }\end{array}$} \\
\hline & $n$ & Odds ratio & $n$ & Odds ratio & $n$ & Odds ratio \\
\hline \multicolumn{7}{|l|}{ Age (years) } \\
\hline $20-29$ & 67 & $2 \cdot 76(1.29-5.92)$ & 59 & $2 \cdot 78(1 \cdot 24-6 \cdot 26)$ & 13 & $1 \cdot 74(0 \cdot 48-6 \cdot 22)$ \\
\hline $30-39$ & 74 & $1 \cdot 87(0 \cdot 95-3 \cdot 67)$ & 58 & $2 \cdot 01(0 \cdot 97-4 \cdot 18)$ & 24 & $1 \cdot 57(0 \cdot 53-4 \cdot 58)$ \\
\hline $40-49$ & 33 & 1 (ref.) & 27 & 1 (ref.) & 9 & 1 (ref.) \\
\hline $50-64$ & 40 & $3.66(1.49-8.97)$ & 35 & $3 \cdot 48(1 \cdot 34-9 \cdot 0)$ & 13 & $2 \cdot 54(0 \cdot 65-9 \cdot 92)$ \\
\hline \multicolumn{7}{|l|}{ Education } \\
\hline Never & 75 & 1 (ref.) & 63 & 1 (ref.) & 23 & 1 (ref.) \\
\hline Low & 74 & $1 \cdot 30(0 \cdot 69-2 \cdot 44)$ & 62 & $1 \cdot 30(0 \cdot 69-2 \cdot 44)$ & 19 & $1 \cdot 29(0 \cdot 46-3 \cdot 66)$ \\
\hline Intermediate and high & 62 & $0 \cdot 90(0 \cdot 47-1 \cdot 74)$ & 52 & $0 \cdot 90(0 \cdot 47-1 \cdot 74)$ & 16 & $0 \cdot 91(0 \cdot 30-2 \cdot 78)$ \\
\hline \multicolumn{7}{|l|}{ Native language } \\
\hline Nengue tongo languages & 96 & $1 \cdot 23(0 \cdot 63-2 \cdot 41)$ & 80 & $1 \cdot 07(0 \cdot 53-2 \cdot 15)$ & 28 & $1 \cdot 95(0 \cdot 57-6 \cdot 71)$ \\
\hline Amerindian languages & 72 & $1 \cdot 27(0 \cdot 64-2 \cdot 51)$ & 61 & $1 \cdot 24(0 \cdot 61-2 \cdot 51)$ & 19 & $1 \cdot 88(0 \cdot 55-6 \cdot 45)$ \\
\hline Portugueuse & 30 & 1 (ref.) & 26 & 1 (ref.) & 6 & 1 (ref.) \\
\hline Others & 16 & $1 \cdot 20(0 \cdot 52-2 \cdot 76)$ & 12 & $0 \cdot 76(0 \cdot 3-1 \cdot 9)$ & 6 & $2 \cdot 96(0 \cdot 76-11 \cdot 48)$ \\
\hline \multicolumn{7}{|l|}{ Age at first sexual intercourse } \\
\hline$<15$ years & 36 & 1 (ref.) & 31 & 1 (ref.) & 6 & 1 (ref.) \\
\hline $15-17$ years & 78 & $1 \cdot 18(0 \cdot 71-1 \cdot 97)$ & 67 & $1 \cdot 14(0 \cdot 67-1 \cdot 94)$ & 21 & $1 \cdot 90(0 \cdot 72-5 \cdot 01)$ \\
\hline$\geqslant 18$ years & 28 & $1 \cdot 34(0 \cdot 69-2 \cdot 59)$ & 23 & $1 \cdot 14(0 \cdot 57-2 \cdot 28)$ & 11 & $4(1 \cdot 29-12 \cdot 45)$ \\
\hline \multicolumn{7}{|c|}{ No. of sexual partners in past year } \\
\hline 0 & 19 & 1 (ref.) & 17 & 1 (ref.) & 7 & 1 (ref.) \\
\hline 1 & 128 & $1 \cdot 33(0 \cdot 58-3 \cdot 01)$ & 108 & $1 \cdot 00(0 \cdot 44-2 \cdot 27)$ & 32 & $1 \cdot 26(0 \cdot 33-4 \cdot 85)$ \\
\hline$\geqslant 2$ & 22 & $1 \cdot 32(0 \cdot 50-3 \cdot 54)$ & 19 & $1 \cdot 01(0 \cdot 37-2 \cdot 75)$ & 6 & $1 \cdot 77(0 \cdot 36-8 \cdot 74)$ \\
\hline \multicolumn{7}{|l|}{ Parity } \\
\hline $0-1$ & 36 & 1 (ref.) & 34 & 1 (ref.) & 8 & 1 (ref.) \\
\hline $2-3$ & 58 & $0 \cdot 86(0 \cdot 45-1 \cdot 63)$ & 47 & $0 \cdot 75(0 \cdot 39-1 \cdot 45)$ & 16 & $0 \cdot 65(0 \cdot 21-2 \cdot 00)$ \\
\hline $4-5$ & 51 & $1 \cdot 03(0 \cdot 51-2 \cdot 07)$ & 43 & $0 \cdot 76(0 \cdot 37-1 \cdot 56)$ & 11 & $1 \cdot 08(0 \cdot 34-3 \cdot 46)$ \\
\hline$>5$ & 69 & $1 \cdot 46(0 \cdot 68-3 \cdot 14)$ & 55 & $1 \cdot 02(0 \cdot 46-2 \cdot 23)$ & 24 & $1 \cdot 78(0 \cdot 51-6 \cdot 25)$ \\
\hline \multicolumn{7}{|l|}{ Contraceptives } \\
\hline Never & 135 & 1 (ref.) & 117 & 1 (ref.) & 38 & 1 (ref.) \\
\hline Oral & 39 & $1 \cdot 12(0 \cdot 61-2 \cdot 06)$ & 31 & $1.04(0.55-1.98)$ & 10 & $0 \cdot 90(0 \cdot 31-2 \cdot 61)$ \\
\hline Others & 40 & $1 \cdot 14(0 \cdot 62-2 \cdot 08)$ & 31 & $0 \cdot 93(0 \cdot 49-1 \cdot 78)$ & 11 & $1 \cdot 4(0 \cdot 52-3 \cdot 77)$ \\
\hline \multicolumn{7}{|l|}{ Smoking } \\
\hline No & 204 & 1 (ref.) & 173 & 1 (ref.) & 55 & 1 (ref.) \\
\hline Yes & 10 & $1 \cdot 05(0 \cdot 40-2 \cdot 77)$ & 6 & $2 \cdot 72(0 \cdot 75-9 \cdot 81)$ & 4 & $0 \cdot 25(0 \cdot 07-0 \cdot 96)$ \\
\hline
\end{tabular}

that in women aged 30-39 years, intermediate or high education were independently associated with a lower risk of having a positive HPV test. A reported number of sex partners $\geqslant 2$ in the past year was associated with an increased risk of having a positive HPV test in women aged $30-39$ years.

\section{DISCUSSION}

The overall prevalence of HPV infection in the remote areas of this French territory was much higher than in mainland France. Moreover, the standardized HPV prevalence rate was comparable to, and even higher than in published studies around the world [10]. The observed level of prevalence was comparable to what is usually observed in developing countries. High HPV prevalence levels are consistent with the high incidence of cervical cancer observed in French Guiana, which also resembles more what is observed in developing countries than what is seen in France. The age at first sex was lower than in mainland France, with differences between the Maroon regions and the Amerindian regions.

The HPV prevalence varied according to age, and seemed highest in the Maroon villages. As observed 
elsewhere, and notably in Latin America and Africa, there was a U-shaped curve of HPV prevalence by age group [11, 12]. The prevalence rate reflects the combination of incidence, new infections, and the duration of infection. The $U$ shape may have reflected new infections in these age groups and/or a slower clearance of viruses in older parous women [13]. As seen in earlier studies, apart from age no other variable was significantly associated with the risk of having a positive HPV test $[13,14]$.

The study limitations were that participation in the study was voluntary, and that women living far from the health centres may have been less likely to be included in the study. Finally, cytology and histology from cervical biopsies would have been important in order to compare the frequency of the genotypes in all women receiving the HPV test and in women with actual cervical lesions. Nevertheless, this is the first study conducted in this border region.

Despite studies repeatedly showing the superior sensitivity of HPV tests over cytology, HPV tests are not reimbursed by French health insurance as screening tools. They are only reimbursed if cytology shows ASCUS lesions or worse. HPV testing can be performed using self-tests, which is less human resource-intensive and could make it more acceptable for some women [15]. Given the high prevalence of HPV infection and the high incidence of cervical cancer in French Guiana, emphasis on vaccination and expanded and innovative screening seems potentially important $[16,17]$. The exact HPV vaccine coverage in these remote territories is unknown, but it is presumably very low. None of the surveyed women reported having been vaccinated. When looking at the variety of HPV genotypes present in these remote territories of French Guiana, the nonavalent HPV vaccines would seem more appropriate that the bivalent or tetravalent vaccines, which do not cover other circulating high-risk genotypes [18]. This nonavalent vaccine has been recommended in France [19] and it would presumably have an even greater added value in French Guiana. Presently, given the large proportion of the population that does not have health insurance in these remote areas, the cost of the vaccine is prohibitive. Given the present results, health authorities should attempt to overcome these economic obstacles to ensure that these populations have access to this vaccine.

Overall, the present results show that over a third of women were infected with HPV, and that over a quarter of women with high-risk HPV infection had normal cytology. The high prevalence of HPV and the $U$-shaped age-specific prevalence observed in the European outermost region of French Guiana are closer to what is observed in poor tropical countries than in Europe. Given the high incidence of cervical cancer in French Guiana and the relative delay in diagnosis $[6,20]$, these results emphasize the potential importance of vaccination, preferably with a nonavalent vaccine. However, in this region where a large portion of the population has no health insurance, this still represents a challenge. Finally, expanded screening using HPV self-tests may be beneficial given the potential for operational simplification in an isolated region where health resources are limited and overstretched $[15,21,22]$.

\section{ACKNOWLEDGEMENTS}

We thank the health professionals of the Centres Délocalisés de Prévention et de Soins and the Protection Maternelle et Infantile. This project was supported by an European Union Grant (PO FEDER 2007-2013, No. Présage: 30814, Guyane Française.

\section{DECLARATION OF INTEREST}

None.

\section{REFERENCES}

1. Walboomers JM, et al. Human papillomavirus is a necessary cause of invasive cervical cancer worldwide. Journal of Pathology 1999; 189: 12-19.

2. Hantz S, Alain S, Denis F. Anti-papillomavirus vaccines and prevention of cervical cancer: progress and prospects [in French]. Presse Medicale 2005; 34: 745-753.

3. Duport. Epidemiological data on cervical cancer -2008 update. In Sanitaire INdV. INVS, 2008, pp. 1-31.

4. Eluf-Neto J, Nascimento CM. Cervical cancer in Latin America. Seminars in Oncology 2001; 28: 188-197.

5. Roue $\mathbf{T}$, et al. Cervical cancer incidence in French Guiana: South American. International Journal of Gynecological Cancer 2012; 22: 850-853.

6. Douine M, et al. Survival of patients with invasive cervical cancer in French Guiana, 2003-2008. International Journal of Gynaecology and Obstetrics 2014; 125: 166-167.

7. Arrossi S, Sankaranarayanan R, Parkin DM. Incidence and mortality of cervical cancer in Latin America. Salud Publica de Mexico 2003; 45 (Suppl. 3): S306-314.

8. van Melle A, et al. Knowledge, attitudes, behaviors, and practices differences regarding HIV in populations living along the Maroni river: particularities of operational interest for Amerindian and Maroon populations. AIDS Care 2015; 27: 1112-1117. 
9. Nacher M, et al. What is driving the HIV epidemic in French Guiana? International Journal of STD and AIDS 2010; 21: 359-361.

10. Franceschi $\mathbf{S}$, et al. Variations in the age-specific curves of human papillomavirus prevalence in women worldwide. International Journal of Cancer 2006; 119: $2677-$ 2684.

11. Forman D, et al. Global burden of human papillomavirus and related diseases. Vaccine 2012; 30 (Suppl. 5): F12-23.

12. Lazcano-Ponce E, et al. Epidemiology of HPV infection among Mexican women with normal cervical cytology. International Journal of Cancer 2001; 91: 412-420.

13. Molano M, et al. Determinants of clearance of human papillomavirus infections in Colombian women with normal cytology: a population-based, 5-year follow-up study. American Journal of Epidemiology 2003; 158: 486- 494.

14. Lazcano-Ponce E, et al. High prevalence of human papillomavirus infection in Mexican males: comparative study of penile-urethral swabs and urine samples. Sexually Transmitted Diseases 2001; 28: 277-280.

15. Toliman P, et al. Field evaluation of the Xpert ${ }^{\circledR}$ HPV Point of Care Test for the detection of human papillomavirus infection using self-collected vaginal and clinician-collected cervical specimens. Journal of Clinical Microbiology 2016; 54: 1734-1737.
16. Lynge E, et al. What happens when organization of cervical cancer screening is delayed or stopped? Journal of Medical Screening 2006; 13: 41-46.

17. Sankaranarayanan R, et al. HPV screening for cervical cancer in rural India. New England Journal of Medicine 2009; 360: 1385-1394.

18. Londesborough $\mathbf{P}$, et al. Human papillomavirus genotype as a predictor of persistence and development of highgrade lesions in women with minor cervical abnormalities. International Journal of Cancer 1996; 69: 364-368.

19. Riethmuller D, et al. Potential impact of a nonavalent HPV vaccine on the occurrence of HPV-related diseases in France. BMC Public Health 2015; 15: 453.

20. Roué T, Nacher M. Epidemiology of cancer in the tropical areas. In: Tropical Hemato-Oncology. Cham, Switzerland: Springer International Publishing, 2015, pp. 17-23

21. Broberg G, et al. Increasing participation in cervical cancer screening: offering a HPV self-test to long-term non-attendees as part of RACOMIP, a Swedish randomized controlled trial. International Journal of Cancer 2014; 134: 2223-2230.

22. Wright TC, et al. Primary cervical cancer screening with human papillomavirus: end of study results from the ATHENA study using HPV as the first-line screening test. Gynecologic Oncology 2015; 136: 189-197. 